\title{
Omar d’León, la pureza angelical del color
}

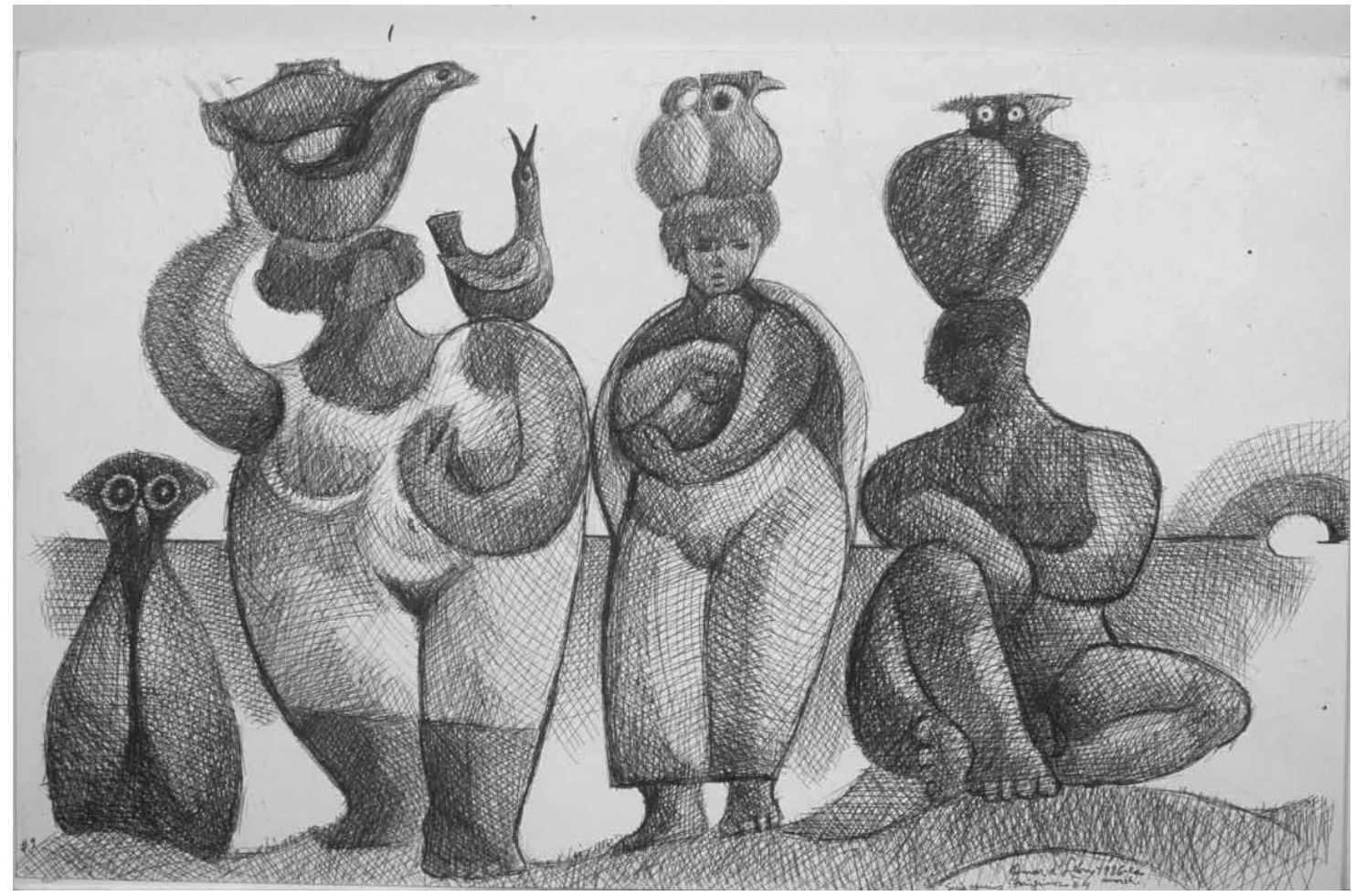

\section{RESUMEN}

En carta de Gómez Sicre de 1978 al Maestro Omar d’León, le dice de los múltiples y controversiales sentimientos que le producen su obra, ubicándola en el linaje de Morandi y Piero Della Francesca. "La ternura, la gracia, el reposo y sobre todo, esa pureza angelical del color me hacen verte en el pináculo de tu trabajo y me tienes, así como suena, rendido a tus pies $(. . .)^{\prime \prime}$.

Palabras clave: ternura, gracia, reposo, sentimiento controversial.

\section{ABSTRACT}

In a letter by Gómez Sicre (1978), sent to Omar d'León, writes on controversial feelings which are made by d'León's work, putting it in the lineage of Monradi and Piero Della Francesca. "The tenderness, grace, rest and above all, that angelic purify of color, make me see you on the pinnacle of your work and I am, as simple as that, surrender at your feet $(. . .)^{\prime \prime}$.

Keywords: tenderness, grace, rest, controversial feeling. 
Gran pintor de corazón y de ideas:

$\mathrm{T}$ u carta por expreso llegó hace dos días. Es enorme la satisfacción que me han dado las diapositivas. Cuando veo una pintura que me toca profundamente, siento una inquietud interna rara. Es algo así como si yo la hubiera ejecutado y me da una gana tremenda de tenerla. En este caso están las seis telas que me das a conocer. Creo que, de tan hondo que me calan, empiezo a sentir envidia de no ser yo el autor, de carecer de talento para darlas como mías. En fin, esos sentimientos en controversia se me producen sólo pocas veces, sólo cuando algo me conmueve. En esta ocasión me has calado hondo. Creo que lo que estás haciendo es un camino de pureza que tiene sólo dos escalones por encima de ti: Morandi y, en un después casi inasible, Piero della Francesca. Ese es el linaje de tu nueva labor y lo voy a decir, [...] La ternura, la gracia, el reposo, y sobre todo, esa pureza angélica del color me hacen verte en el pináculo de tu trabajo y me tienes, así como suena, rendido a tus pies [...].

Ese es el modo que yo reacciono ante lo que considero importante y trascendente en arte y creo que no debes, por el momento, abandonar esa dirección. En pintura los temas no se agotan y pueden repetirse hasta el infinito. Morando siempre tuvo el mismo repertorio de botellas y frascos de loza y de vidrio que plasmaba en sus telas. Yo lo visité varias veces en Bolonia. Las (sic) conservaba sobre una repisa y las pintó durante años. Cada obra, pequeña o grande, es un monumento a la pureza plástica. Cezanne no tuvo más que tres temas en su carrera, con la que transmutó el concepto universal de la pintura de occidente. Para los bodegones conservaba también un equipo inmutable de objetos: un "putto" de yeso, una botella de Chianti, una fuente en blanco y azul. Todo eso lo vi en su última casa donde murió en Aix y, con la religiosa intención lo toqué.

Con esto te digo que sigas con esas frutas pulposas, de contornos imprecisos, vibrantes, esa ternura en su corteza y en su carne (tu versión de la pitahaya me parece maravillosa, quizá el mejor de los cuadros) y esos fondos encalados de coloración indefinida, todo ello me parece extraordinario. Sí quisiera verte llevar esa temática, esa técnica y ese concepto a dimensiones mayores, que rocen con una ambición al mural: digamos 1 x $1.20 \mathrm{mt}$. o más. Quisiera comprar uno para la colección de nuestro Museo. Puedes contar, al menos, con este admirador desbocado y desenfrenado que quiere tu obra de veras. $[\ldots]$
Tiene que haber un dios por los cielos que se ocupe de bendecir a los pintores que no sólo sepan pintar sino que tengan algo profundo que decir. Pues bien, a ése le voy a rogar que se ocupe del Omar de Sade que, en Nicaragua, está pintando como podrían hacerlo los ángeles si se ocuparan de pensar.

Recibe un abrazo por todo eso que has hecho y por lo que seguramente vas a hacer.

José Gómez Sicre

Museum of Modern Arto f Latin American

Organización de los Estados Americanos

Washington D.C.

25 de marzo de 1978
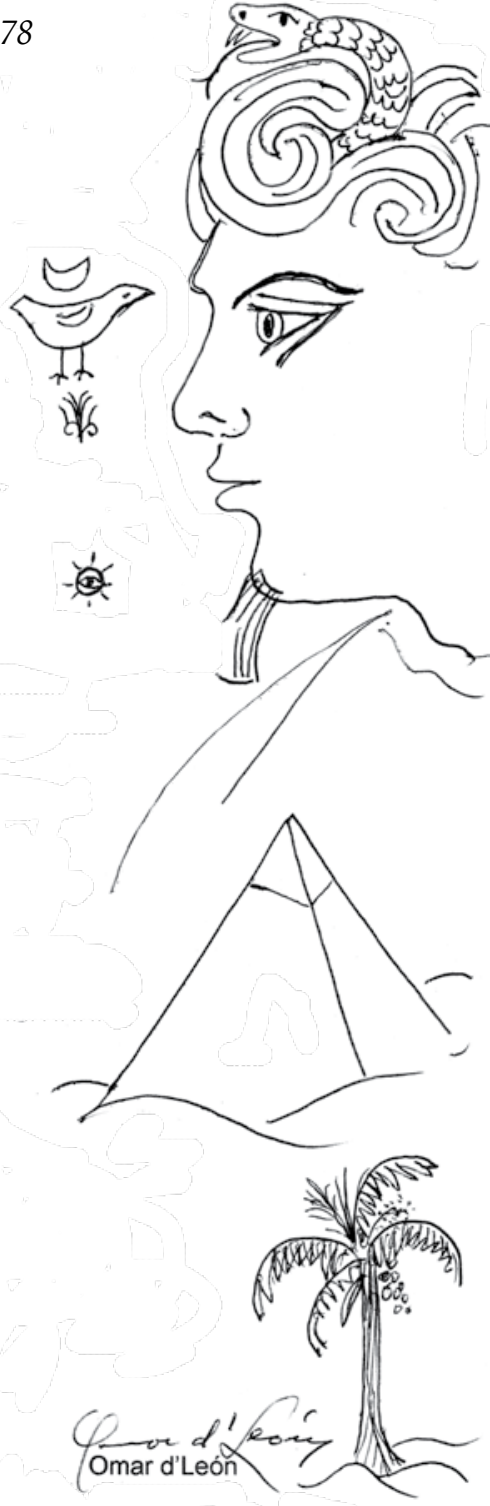